\title{
Black working-class students' negotiation of boundaries across time and space: A longitudinal analysis
}

\author{
Rochelle Kapp ${ }^{1}$ and Bongi Bangeni ${ }^{2}$ \\ ${ }^{1}$ School of Education, University of Cape Town \\ ${ }^{2}$ Centre for Higher Education Development, University of Cape Town \\ Corresponding Author: rochelle.kapp@uct.ac.za
}

(Submitted: 19 November 2019; Accepted: 20 April 2020)

\begin{abstract}
This article critiques representations of black South African students as victims, as colonised by academic discourse or as entitled millennials in the current debates about decolonisation in higher education. It argues that, albeit from different ideological perspectives, such representations depict black students' experiences as homogenised and reified, and separate identity from the processes of learning. We draw on data from two qualitative longitudinal studies to analyse the ways in which black working-class students are positioned by the expected subject positions within the academy and at home. We illustrate the diverse and contradictory ways in which the participants reposition themselves as they straddle the boundaries of home and the academy over time. The article argues that the activity of straddling boundaries and making meaning from a diversity of positions is situated agentic work, and is central to learning, to critical engagement, and to enabling new ways of knowing and being.
\end{abstract}

Keywords: agency, black students, boundaries, identity, learning

\section{Introduction}

Recent South African university protests, namely \#Rhodesmustfall and \#Feesmustfall, have had the welcome effect of raising consciousness around issues of alienation, belonging and social positioning in relation to black students in higher education in South Africa. This focus contrasts to the past where institutions constructed black students' home identities and languages as problems to be fixed (Kapp and Bangeni, 2011) and where, as Pym and Kapp (2013) argue, academic development initiatives have often avoided engagement with identity issues for fear of pathologising black students.

Nevertheless, we argue that the rhetorical representation of black students' experiences in the current climate of 'decolonisation' is problematic, in that black students' identities are often homogenised and reified, albeit from different ideological perspectives. For example, this is evident in Jansen's (2018) decontextualised characterisation of black students as 'entitled 
millenials'; in the polarised, static descriptions of black students as either completely alienated or assimilated in the University of Cape Town's (2018) draft curriculum framework document; and in Maroga's (2019) essentialising depiction of black students as traumatised victims of 'whiteness', which he defines as an 'organic entity' and 'virus', invading the 'black body'. Such deterministic depictions present students' social identities as uniform, static, and singular and fail to represent the complexity and diversity of the lived experiences and identity transitions of black students. These fixed positions reflect a political stance, born out of a history of marginalisation and oppression. They confirm strongly-held positions and assert difference, taking little account of the multiple, fluid (and often conflicting) class, linguistic, gendered, and religious subject positions that students growing up in a post-Apartheid, but still vastly unequal context, negotiate within the academy and in relation to home. In doing so, they separate identity from the processes of learning and erase the ambivalence that is entailed in students' wrestling with conflicting views and ways of being within the multiple domains they navigate over time. Thus, they do not take cognisance of students' meaning-making processes; that is, the agentic work that is crucial to developing new ways of thinking and to enabling societal transformation and change.

On the basis of findings from two qualitative longitudinal research projects which explored how black working class students negotiated identity and learning (Bangeni and Kapp, 2017), and drawing on insights from other recent research on students' experiences in higher education, we describe and analyse some of the complex and contradictory ways in which students engage with 'socially and discursively available resources' (Thomson, 2009: 160). Using the metaphor of boundaries drawn from the work of Carter (2006), Mbembe (2017), Ramphele (1995), and Thornton (1988), we present data from the longitudinal studies and examine the interplay between agency and structure, in order to understand how the 'specifics of context and history translate, in dynamic and unstable ways, into multiplicity and difference in the lives of situated individuals' (Haggis, 2004: 337). We are interested in the ways in which students are positioned by the subject positions expected within their disciplines, the institution and at home. However, we are also interested in the ways in which students position themselves: how they interpret spaces, how they invest in the subject positions that are available to them in certain spaces at certain times, and how they resist others and question strongly-held ways of knowing and ways of identifying. Extracts from the narratives of three participants are used to illustrate participants' multiple transitions and navigation of boundaries. These examples problematise singular, homogenised narratives of black student experience and black pain. We draw on a range of postcolonial and post-structuralist theorists on learning and identity to describe the participants' ambivalence as they negotiate often conflicting discourses within their disciplines, within the institution, and between home and the institution, and occupy multiple subject positions that are related to the boundaries and possibilities of place and time.

\section{The concept of boundaries}

A broad range of post-structuralist theorists argue that ways of knowing, using language and being are situated in time and place and inextricably connected to structures of power (Gee, 
1990; Blommaert, 2010; Norton, 2000; Thomson 2009; Thomson and McLeod, 2015). People create the boundaries of race, class, gender, language that characterise particular spaces at particular times (Carter, 2006; Mbembe, 2017; Ramphele, 1995; Thornton, 1988). The physical places that we inhabit are made social through the activity of constructing norms, values and concomitant subject positions (Canagarajah, 2018). Yet, while boundaries are a social construction, over time they come to seem real and are internalized, sedimented, and reproduced through socialization (Carter, 2006; Mbembe, 2017; Ramphele, 1995; Thornton, 1988). They are treated and experienced as real. In Mbembe's (2017: 183) words:

Difference is, in most cases, the result of the construction of desire. It is also the result of a work of abstraction, classification, division and exclusion - and a work of power that, afterward, is internalised and reproduced in the gestures of daily life, even by the excluded themselves.

Importantly, as Thornton (1988) and Mbembe (2017) argue, boundaries are made more visible and treated as real in struggles for power when people feel excluded. They are emphasised and more vigorously policed to assert rights, entitlement and access to physical and cultural resources and social goods. Mbembe (2017: 183) argues that in these conditions, the proclamation of difference is an inverted expression of the desire for recognition and inclusion'.

As both Thornton (1988) and Gee (1990) point out, boundaries are also made more visible to people when they step outside of the discourses that characterise their primary socialisation. While the limits, of boundaries may become more apparent to students through the experience of being excluded, we have found that the norms, values, ways of constructing knowledge and ways of being and interacting in multiple spaces are often difficult for students to name and access when they first enter the university (Bangeni and Kapp, 2011). As Mendelowitz and Dixon (2016) and Mendelowitz (2017) point out, stepping outside of one's primary discourse may indeed have the effect of reinforcing existing stereotypes and prejudice. It may also lead to assimilation. However, if mediated, the process has the potential to be transformative, to enable access to productive comparison, meta-knowledge and to critique.

Our analyses of students' trajectories have helped conceptualize students' paths into the institution as a journey in which they have to navigate boundaries and traverse multiple physical and social spaces as they move between home and the institution. In Giroux's (1991: 53) terms, students must cross borders 'into realms of meaning, maps of knowledge, social relations, and values..... In doing so, they have to negotiate an intersection of (often conflicting) race, class, gendered and religious subject positions and 'while the institution provides a roadmap, it is fairly rudimentary, seldom sufficiently explicit and primarily based on normative (usually white, middleclass, English) assumptions about students, their ways of being, learning, home and schooling contexts' (Bangeni and Kapp, 2017: 2). Drawing on the evolving meanings participants attribute to their learning journeys over time and in the different spaces they inhabit allows us to explore 
how students' ability to be agentic is enabled and/or constrained by the academy and home at different times.

\section{The concept of agency}

A number of recent, qualitative studies on student experiences in higher education have highlighted the significance of student agency (see Bangeni and Kapp, 2017; Case, et al., 2018; Klemenčič, 2015; Sabri, 2011; Swartz, et al., 2018; Walker and Mathebula 2019). These studies have demonstrated the ways in which students' choices and opportunities are structurally constrained by their race, social class and gender backgrounds as well as the white, middle-class, urban metropolitan norms, values and academic literacy practices that characterise many higher education institutions. Nevertheless, they also demonstrate how structural constraints shape, but do not necessarily overdetermine students' identities. In Thomson's (2009: 154) words, individuals' lives are both 'constrained' and 'agentic'. Individuals have the ability to 'actively create their worlds, but they do so in particular conditions and circumstances that are already structured by history' (Christie, 2008: 6). This conception is captured in Maxwell and Aggleton's, (2013: 3) assertion that theorizing agency entails understanding 'the interface between factors structuring and producing action'.

Klemenčič (2015: 16) writes persuasively about the situated nature of students' agency. She defines agency as

... a process which encompasses variable notions of agentic orientation ("will"), the way students relate to past, present and future in making choices of action and interaction, and of agentic possibility ("power"), that is their perceived power to achieve intended outcomes in a particular context of action and interaction... ..

As such, she argues for a view of agency which considers its spatial and temporal nature. According to Klemenčič (2015:18), agency is 'temporally embedded ... Student agency includes students' selective reactivation of past habits of thought and action, students' imaginative generation of possible future selves, and students' capacity to make practical and normative judgments among possible choices of action'. Conceptualising agency as situated points to the contexts within which students engage, 'contexts of interdependent educational, political, social, economic and cultural conditions that present unique opportunities, constraints and challenges to student agency' (Klemenčič, 2015: 19). This conceptualization of agency foregrounds the disproportionate distribution of power in particular spaces, which serve to position individuals at the center or margins thereof (see hooks, 1984).

Drawing on three examples in particular, this article argues that as they traverse multiple boundaries, students are involved in a cognitive and affective process in search of a place, a position that enables them to seem to reconcile past and present and provide options for the future. This activity entails both absorbing and resisting new discourses and it entails strategic and instrumental decision-making about how they wish to locate themselves physically, 
intellectually and emotionally. In effect, the students straddle boundaries. We argue that the activity of straddling boundaries and making meaning from a diversity of positions is agentic work and is an essential part of learning and of university education. Through the activity of straddling boundaries, students question previous certainties and are actively engaged in developing new ways of knowing and of being.

\section{Methodology}

This article draws on data and findings from two collaborative qualitative longitudinal case studies conducted at the University of Cape Town which traced the learning experiences of 120 black working-class students over the course of their undergraduate years (reference omitted for review). Both studies draw on background questionnaires, semi-structured interviews with students in each year of their study; students' written reflections on language and writing, as well as course assignments selected by students each year. For the purposes of this article, we draw on the semi-structured interviews which asked participants to describe their home and school backgrounds, their lives within the university, their interests, their approaches to learning, their assessment of their progress, and their sense of their future paths. Participants were given access to prior transcripts of their interviews each year and asked to reflect and comment on their sense of continuity and change in their relationships, their approaches to learning, and their positioning within their home, disciplinary, and institutional contexts.

Thomson (2009: 16) argues that the qualitative longitudinal study is a method which is particularly suited to capturing the 'subject in process'. She describes interviews as 'snapshots of particular times and places', and argues that whereas single interviews of participants tend to freeze participants' images in particular times and places, multiple interviews enable snapshots 'to be articulated, providing a timescape' that enables one to see how individuals reflect, position and reposition themselves (Thomson, 2009: 150). The longitudinal data set 'disrupts narrative smoothing' as 'new data constantly tests the validity of earlier interpretations' (Thomson, 2009: 133). The effect of repeated interviews was to allow us to see both continuity and change (Thomson and Holland, 2003). The extracts from the three cases used in this article were chosen because they exemplify the diversity of experiences, positions, issues, and structural constraints that are described by the participants as they negotiated the boundaries of home and the academy. While participants' trajectories are individual, their ways of responding to institutional discourses change over time. The active meaning-making and resourcefulness evident in these three cases, is typical of the overall data (see Bangeni and Kapp, 2017).

Our research does not assume that we can read off participants' identities from the interviews or establish an essential truth. Alongside other poststructuralist theorists, we are mindful of the positions from which participants reinterpret their identities in interviews as they reposition themselves in the light of past and present contexts and in their projections of possible futures (see Herrington and Curtis, 2000; Norton, 2000; Sfard and Prusak, 2005). We are interested in how the participants described their experiences, the issues that they chose to 
foreground, and how they constructed a sense of self in relation to others in the different spaces they navigated over time.

\section{Negotiating the boundaries of the school to university transition}

The academic, linguistic and psycho-social challenges of the school to university transition have been described by many studies globally. In South Africa, studies have particularly illustrated the ways in which black students' opportunities are limited and confined by boundaries of language, schooling, race, class and gender (Calitz, et al., 2016; Case, et al., 2018; Fataar, 2018; Swartz, et al., 2018; Pym and Paxton, 2013; Wilson-Strydom, 2015; Walker and Mathebula, 2019). Our data confirm many of these findings, illustrating how language, ethnicity and race were the most visible boundaries to students when they first entered the university, as in the following description of the institutional environment: 'It's white and you don't get to speak your language very easily'. Participants who had attended working-class black township schools were often positioned in deficit terms by the institutional discourses, silenced by the Englishness and 'whiteness' of the institution, and by the rejection of the norms and values of their home discourses within disciplines and socially. This rejection was also experienced in relation to more middle-class African language speakers, as in the case of a participant who was accused by a fellow student of being 'too loud and black'.

The data from the first six months of participants' first year of university reflect their intense alienation from institutional and disciplinary norms and values, as well as the ways in which participants' learning was impeded by the rote-learning that characterised their schooling, by being obliged to learn through the medium of English, by academic structures such as limitations of choice within degree structures, and by lack of finances. Participants' ability to access new knowledge and to participate was also limited by pedagogic practices such as lack of explicitness about intended pedagogy, lack of clarity about how processes of knowledge construction within the discipline are connected to language, literacy and numeracy practices; lack of conceptual coherence within and between courses; and lack of alignment between pedagogy and assessment.

The data show the ways in which students felt positioned, silenced and rendered passive by disciplinary discourses which seemed to assume assimilation, offering very limited scope for debate and alternative positions. This is reflected in participants' assertions that despite being encouraged to debate within Humanities, essay topics assumed a particular ideological stance, prescribing the subject position and the evidence which would be regarded as authoritative. This experience is evident in the words of one participant: 'the essay topic is structuring me' and in another participant's (final year) reflective comment that in his first year: '...I simply reproduced what the tutors taught me about the subject, my writing was largely shaped by tutor's ideas, mine were scarce'. Disciplines often constructed undergraduate students as outsiders to knowledge production. Lecturers made assumptions about students' prior knowledge and experience, but seldom engaged them on the subject. Negative feedback resulted in participants mimicking the 
discourses of their disciplines and adopting strategic and reproductive subject positions in order to pass (Kapp and Bangeni, 2011).

This relatively familiar narrative of alienation and consequent assimilation described in many qualitative studies is an important one. It speaks to the inextricable connection between learning and identity, the ways in which institutions expect reproduction and construct students in deficit terms, and the ways in which students' home discourses are marginalized and excluded (see also Boughey, 2009; Case, et al., 2018; Pym and Paxton, 2013; Swartz, 2018). However, the longitudinal perspective of our research has enabled us to see that this narrative of students' initial transition into institutions is partial and provisional.

In the next section we draw on three examples from our research to illustrate how the temporal and spatial nature of agency became evident in students' negotiations of boundaries within the spaces of home and university as they made sense of school and home values and practices in relation to those of the institution. The three students, Zinhle, Roshni, and Babalwa (all pseudonyms) were first-generation working-class students. In presenting the data we show how students' ways of responding to institutional discourses change over time in response to the ways in which they have been positioned, in response to their processes of straddling boundaries and as a consequence of changing subjectivities and positionalities.

\section{Negotiating the boundaries between home and university Zinhle's journey}

Zinhle is a Xhosa speaker who was accepted into Occupational Therapy. She came to the university from a rural village and was the only person from her school to do so. She was actively discouraged by her teachers from applying to the university: 'They told me you are not going to make it'.

Zinhle failed her first semester and attributed this to her struggles with English, academic literacy, and the social norms and values of the institution. Klemenčič's (2015) conceptualisation of agency considers the resources on which students draw from contexts external to the institutions in which they engage, and how these shape their actions therein. In her first interview (conducted after she failed), Zinhle juxtaposed her home environment and values with her life at university. She foregrounded her identity as 'rural' and repeated this description in subsequent interviews. Zinhle's notion of this identity was multi-faceted. Firstly, the term 'rural' was used to signify her structural constraints. She spoke of growing up in poverty in a rural village with her parents and five sisters. Zinhle attended a school with minimal resources in another village where class-sizes averaged 55 learners: 'I was studying at a rural area school, a poor primary school ... for my personal needs, I didn't get everything I liked but I understood that there's no money' (see van Rensburg and Kapp (2014) for more detail).

For Zinhle, being 'rural' also signified a set of values, attitudes and behaviour which she believed characterised her as different from others at university and served as a moral code. In her second interview, she emphasised the set of Christian norms and values that enabled her to place limits on her behaviour and maintain the home norms and values that her parents would 
expect of her. She verbalised strong awareness of the subject position expected by her parents: 'I am a rural girl and you know those rules ...'. While it seemed that Zinhle was merely conforming to expected gender and religious norms, she also actively distanced herself from the materialism she noticed among her peers within the university environment and asserting: 'I see myself as smart when I am wearing this R30.00 skirt, it is fine for me and I don't even feel inferior when I'm walking with someone who is wearing all those labels'.

Although Zinhle described in detail the constraints of growing up without resources and opportunities both at home and school in great detail, she did not conceptualise her role and status as a 'rural girl' in terms of being a victim. She consistently positioned herself as a firstgeneration student from her family and community and therefore as an agent of change for her family and her community. In her first interview she asserted her sense of obligation and responsibility very clearly 'I'm the only one who has to change the situation of my family because it's poor'. She envisaged herself as both primary wage-earner and as a leader in her community. Her choice of Occupational Therapy was purposeful, and reflected her strong sense of 'rural' identity: '...because I'm coming from a rural area... I have chosen this because of physically disabled people... they don't have money to buy like wheelchairs, they don't have money to buy tools to adapt to the environments, so that's why I decided to do Occupational Therapy, so that at least people who are poor from my background... can benefit from this type of provision'.

Zinhle was sustained by the notion of a future self as a change agent over the next five years of university. For the most part, she preserved strong boundaries between home and university, and maintained a narrative of overcoming adversity, despite her early failure. She worked out the literacy of Occupational Therapy discourses by learning to draw on available academic and social resources, by attaching herself to a mentor and by working long hours, often isolating herself to do so. She kept contact with home, but in a circumscribed manner. She refrained from telling her family of her difficulties and tried to limit her contact with them to allay her own sense of guilt about being in a more privileged position than those at home.

By her final year, she envisaged a future where she would eventually play a structural role in effecting change within a rural primary healthcare context: 'Now it is not only about passing, it is about acquiring knowledge and applying it outside, like now I am thinking out of the box'. She articulates a clear sense that the discipline had taught her professional skills and values 'about prejudice and stereotypes' which had broadened her 'mindset'. She was strongly critical of the ways in which prejudice impeded healthcare in her community. The notion of being agentic within her community seemed to play a crucial role in her sense of self, her persistence and her successful graduation.

\section{Roshni's journey}

In contrast to Zinhle's early emphasis on retaining her home identity, many participants were excited by choices offered within the university environment and the possibility of being able to claim identities often considered illegitimate within their working-class school and home environments. This is illustrated by the case of Roshni, a first-generation Muslim student and 
Afrikaans speaker from a gang-infested township in Cape Town. Similar to Zinhle, Roshni came from a severely under-resourced school environment with low expectations of its learners. In her description, the expected career path was that: 'After school you go work in a factory, after school you go work in a shop'. Roshni had never conceived of going to university, indeed had never heard of the University of Cape Town prior to accompanying friends on a visit to the institution's Open Day in her final year of school.

Roshni deliberately sought to reinvent herself within the university environment and to make full use of opportunities. She was fascinated by difference and the diversity within the university environment. In her first year, she spoke excitedly about transcending conventional academic and social boundaries by making new friends across racial, class, and national boundaries. She registered for courses that 'made me grow more personally and individually and socially'. Whereas Zinhle isolated herself and refrained from asking for help in her first year, Roshni was highly social and vocal. She used institutional resources, sought out staff members for help, and participated actively in lectures.

What is interesting is the way in which Roshni, like many other women students, straddled the boundaries of home and institutional discourses in her attempt to create coherence from seemingly contradictory identities (Sacks and Kapp, 2017). In each of her three interviews, Roshni drew from the language of popular discourse and from her academic subjects (in particular Psychology), to describe how she saw herself engaged in a process of self-discovery and reinvention. In her second year, she described her first year as a process of 'finding my identity, developing who I am'. She spoke enthusiastically about the University as a place that had expanded her physical, intellectual and social horizons. Significantly for Roshni and many women students, exposure to academic discourse enabled nascent or even direct critique of home cultures and oppressive positioning of women. Roshni could not simply be described as assimilated. An enormous amount of intellectual and emotional resources went into her project of re-fashioning an identity which would also take into account her home identity as a Muslim, working-class woman. For example, Roshni chose gender related courses 'because in my religion males are practically dominant'. Simultaneously, she registered for Arabic and constructed a possible future in which the disparate subject positions made available by home and the academy could be merged. Her rationale was as follows:

...Arabic is what I'm supposed to know as a Muslim, I'm supposed to know it... and that's personal and it's also beneficial because I can go to the United Arab Emirates or any Arabic country. As a woman, you don't have anything, but if you have knowledge you can go far because you have Arabic and in that country you can do teaching...

In her second year, Roshni had to take over household duties, care for her schizophrenic sister, and earn a salary while her mother went on pilgrimage to Mecca. In contrast to her customary ebullience, Roshni dealt with the stress of this burden alone. In an interview later in the year, she said: '...you come to campus you fake it, you don't show anyone your problems, 
you smile, you don't cry, you make sure that you strong, no one sees you cry... because you are firm, because you are a woman you can take it... that's what you supposed to... . You say that over and over to yourself...you are a woman, you are a rock, you are supposed to handle this...'. Here, Roshni articulated the emotion work entailed in her attempt to navigate multiple, conflicting identities. She harnesses feminist, anti-Apartheid struggle discourse -- 'woman you are a rock' - - to critically analyse herself and confirm her entrapment. Similar to other participants, Roshni struggled with the expectation that she would remain the same, conform to home expectations and engage with new identities (see also Lucey, et al., 2003; Reay, 2001).

The longitudinal perspective enables one to see the boundary work entailed in negotiating and rationalising subjectivity across time and space. Roshni's agency was situated and limited, but she constantly worked with the possibilities offered to her to fashion ways of being that would enable her to create a sense of belonging and purpose in both places and to construct a future sense of self.

\section{Babalwa's journey}

Babalwa's case further illustrates the complex, multi-faceted nature of participants' negotiation of boundaries. In her first year, she foregrounded academia as a means to upward mobility and was frustrated by the failure within Humanities' disciplines to provide clear answers, which would enable her to pass and fulfil her goal of upward mobility. This is reflected in her impatience with Philosophy where: '... you keep on debating because there's no answer.... They [academics] say they don't look at the outcome, but in a way you are because you are using education as a means to go'.

This position contrasts sharply with Babalwa's statement in her final year thatthat: 'I have grown to realise that what I have been taught about God, females and males, the world is not necessarily what it is and that what I believe in is not necessarily true or wrong - not everything is black and white... I have learnt that human beings are not passive; they question things, its roots and how things become universally accepted (the norm)'. This statement suggests a significant shift in Babalwa's understanding of the value of social science discourse and a questioning of her home discourses. However, in her interview later in the same year, Babalwa spoke of learning to question gender identity through academic discourse, but also of how she resumed the expected passive gender role each time she returned to her family home.

The data are replete with such images of students' negotiating difference by 'oscillating between fixity and openness' (Bank, 2011: 12). Participants' experiences were characterised by ambivalence. They seemed to absorb and resist the discourse of their academic disciplines and home. As Carter (2006: 305) points out, when research applies 'binary markers' to black students, 'their explanations frequently obscure the heterogeneous cultural and educational experiences of students'. 


\section{Straddling boundaries, learning and identity}

The data illustrate how conflicting expectations about subject positions and learning identities shape participants' participation, attitudes and decisions. However, while discourses create subject positions that are powerful and constraining, they are not necessarily over-determining. The longitudinal lens enables us to see the ways in which individuals are positioned and the ways in which they reposition themselves in relation to their pasts, their unfolding sense of a future self and in relation to conflicting discourses.

The participants' lives are 'implicated and constrained, yet also agentic and undetermined' (Thomson, 2009: 154). They use their knowledge of multiple discourses as a resource to straddle conventional boundaries in order to reposition themselves to create a meaningful sense of self within their home environments and to gain access to academic discourses. The students' readings of themselves and their world change as a result of their experiences of straddling boundaries.

While we conventionally think of boundaries as edges (Thornton, 1988), the data show that the activity of straddling real and imagined boundaries is central to the trajectory of workingclass students. Transgression of boundaries is essential to transformation, but does always include risk (Habib, 2019; Mbembe 2017; Ramphele 1995). It entails confronting multiple and contradictory ways of knowing and negotiating ambivalence. Agency is, in the words of Mbembe (cited in Goldberg, 2018: 212) a matter of '...knowing when and how to cross over'.

The data problematize singular narratives of student experiences in which they are positioned as traumatised victims, as colonised by academic discourse, or as entitled millennials. Many students are indeed traumatised and alienated as they confront unacceptable structural obstacles in their transition to university. Their voices are often silenced and their ways of knowing and using language are positioned as marginal and deficit. However, what the data also show us is that, over time, participants are neither simply assimilated nor alienated by academia. The act of transgressing boundaries is not singular, and students' paths are not linear. Participants are travelling and engaging in multiple transitions.

In that process, they are actively critiquing, strategizing, choosing how they will use resources, and they are reflecting on their contradictory experiences in order to figure out who they are, what they believe and what social roles they wish to play in society. Disciplinary and institutional discourses constrain them, but also enable new ways of conceptualising and critiquing. This is an essential part of being a university student, of breaking new boundaries in order to transgress. It is agentic work. In the words of Robin Kelley (2016):

... reading black experience through trauma can easily slip into thinking of ourselves as victims and objects rather than agents, subjected to centuries of gratuitous violence that have structured and overdetermined our very being. In the argot of our day, "bodies"vulnerable and threatening bodies-increasingly stand in for actual people with names, experiences, dreams, and desires. 
The data show that our participants are agentic. However, their agency is situated and they are only able to be agentic in certain times and spaces (Klemenčič, 2015). The task, we argue, is to harness that agency, to facilitate a process which enables them to belong, but also acknowledges the power of not-belonging, of discomfort, of being 'unhomed' (Bhabha, 1994: 44). The term does not imply homelessness but signifies the ambivalent space these students occupied as they straddled multiple (and often conflicting) discourses. The concept of being 'unhomed' captures the sense of occupying an ambivalent space, of 'being in two places at once' (Bhabha, 1994: 44).

We need to acknowledge the questioning of the taken-for-granted, the ambivalence, the meta-knowledge that comes from straddling 'different worlds of experience' (Christie, 2005: 42). Meaningful learning is not about confirming identities and ways of knowing. The task is not to romanticise or reify home or institutional discourses, but to acknowledge and engage with ambivalence and contradictions, to move away from narrow, simplistic binary notions of difference that are the result of the boundaries being treated as real and, consequently sedimented (Mbembe, 2017; Thornton, 1988).

Identity is central to learning and to epistemic access. However, learning is a process of enquiry, of challenging boundaries, of exploring limits. By emphasising identity only, decolonial activists have curiously also obscured a very real, structural problem which lies at the heart of the South African higher education system, that of black student participation and retention (Council on Higher Education, 2013). To address this, we have to take the multi-faceted, situated nature of identity into account; we have to interrogate the content that we teach, but we also have to interrogate pedagogy - the assumptions that are made about prior knowledge, the tacit ways in which students are included and excluded within the academic conversation and the ways in which we assess for learning. The boundaries are not real, however much their edges appear clear cut and visible. To transform higher education, we have to acknowledge, openly and honestly, the ambivalence and the contradictions and the consequent straddling and repositioning work that are all, as Thornton (1988:28) argues, 'at the centre' of negotiating the boundaries.

\section{Acknowledgements}

This research was funded by the A.W. Mellon Foundation.

We are grateful to Profs Pam Christie and Kelwyn Sole for helpful comments on an earlier version.

\section{Author Biographies}

Rochelle Kapp is an associate professor in the School of Education, University of Cape Town. She has extensive experience in the fields of language, literacy and teacher education and academic development. She has published in the areas of literacy practices, student experience, writing and identity and the politics of English. 
Bongi Bangeni is associate professor in the Centre for Higher Education Development, University of Cape Town, South Africa, and a Mandela Fellow at the Hutchins Center for African \& African American Research, Harvard University, USA. She has published on writing and identity and black students' transitions from undergraduate to postgraduate studies.

\section{References}

Bangeni, B. \& Kapp, R. (eds.) 2017. Negotiating Learning and Identity: A Longitudinal Perspective on Access, Persistence and Retention in Higher Education. UK: Bloomsbury Publishing.

Bank, L. 2011. Home Space, Street Styles. Johannesburg: Wits University Press.

Bhabha, H. 1994. The Location of Culture, London: Routledge.

Blommaert, J. 2010. The Sociolinguistics of Globalization. Cambridge: Cambridge University Press. Boughey, C. 2009. A meta-analysis of teaching and learning at the five research-intensive South African universities not affected by mergers. Pretoria: Council on Higher Education, Available at https://www.ru.ac.za/media/rhodesuniversity/content/politics/documents/ (accessed 14 April 2016).

Calitz, T., Walker, M. \& Wilson-Strydom, M. 2016. Theorising a capability approach to equal participation for undergraduate students at a South African university. Perspectives in Education, http://dx.doi.org/10.18820/2519593X/pie.v34i2.

Case, J., Marshall, D., McKenna, S. \& Mogashana, D. 2018. Going to University: The Influence of Higher Education on the Lives of Young South Africans. Cape Town: African Minds.

Carter, P. 2006. Straddling boundaries: Identity, culture and school. Sociology of Education, 79 : 304-328

Christie, P. 2005. Education for an ethical imagination. Social Alternatives, 4(4): 39-44.

Christie, P. 2008. Changing schools in South Africa: Opening the Doors of Learning. Johannesburg: Heinemann.

Council on Higher Education. 2013. A Proposal for Undergraduate Curriculum Reform in South Africa: The Case for a Flexible Curriculum Structure. Available at http://www.che.ac.za/sites/default/files/publications/ (accessed 18 July 2018).

Canagarajah, S. 2018. English as a spatial resource and the claimed competence of Chinese STEM professionals. World Englishes and Second language Acquisition, 37(1): 34-50.

Fataar, A. 2018. Placing students at the centre of the decolonizing education imperative: engaging the (mis)recognition struggles of students at the postapartheid university. Educational Studies, 54(6): 595-608.

Goldberg, D. 2018. 'The reason of Unreason': Achille Mbembe and David Theo Goldberg in conversation about Critique of Black Reason. Theory, Culture \& Society, 35(7-8): 205-227.

Gee, J. 1990. Social Linguistics and Literacies: Ideology in Discourses. London: Falmer.

Giroux, H. 1991. Border pedagogy and the politics of postmodernism. Social Text, 28: 51-67.

Habib, A. 2019. Rebels and Rage: Reflecting on \#FeesMustFall. Johannesburg: Jonathan Ball.

Haggis, T. 2004. Meaning, identity and 'motivation': expanding what matters in understanding learning in Higher Education. Studies in Higher Education, 29(3): 335-352. 
Herrington, A. \& Curtis, M. 2000. Persons in Process: Four Stories of Writing and Personal Development in College. Urbana, Illinois: National Council of Teachers of English.

hooks, B. 1984. From Margin to Center. Boston, MA: South End Press.

Jansen, J. 2018. Our fragile students wallowing in self-pity need a history lesson. Times Live, 9 September. Available at https://select.timeslive.co.za/ideas/2018-09-20-our-fragilestudents-wallowing-in-self-pity-need-a-history-lesson/ (accessed 18 July 2019).

Kapp, R. \& Bangeni, B. 2011. A longitudinal study of students' negotiation of language, literacy and identity. Southern African Linguistics and Applied Language Studies, 29(2): 197-208.

Kelley, R. 2016. Black Study, Black Struggle. Boston Review, 7 March. Available at http://bostonreview.net/forum/robin-d-g-kelley-black-study-black-struggle (accessed 4 August 2018).

Klemenčič, M. 2015. What is student agency? An ontological exploration in the context of research on student engagement. In Klemenčič, M., Bergan, S. \& Primožič, R. (eds.) Student Engagement in Europe: Society, Higher Education and Student Governance. Council of Europe Higher Education Series No. 20. Strasbourg: Council of Europe Publishing, 11-29.

Lucey, H., Melody, J. \& Walkerdine, V. 2003. Uneasy hybrids: psychosocial aspects of becoming educationally successful for working-class young women. Gender and Education, 15(3): 285-299.

Maxwell, C. \& Aggleton, P. (eds.) 2013. Privilege, Agency and Affect: Understanding the Production and Effects of Action. New York: Palgrave Macmillan.

Maroga, K. 2018. Black Artist: Towards an Epidemiology of Institutional Whiteness. Artthrob, 14 April. Available at https://artthrob.co.za/2018/04/24/performative-politics-and-thecommoditisation-of-the-black-artist-towards-an-epidemiology-of-institutionalwhiteness/ (accessed 18 July 2019).

Mbembe, A. 2017. The Critique of Black Reason. Johannesburg: Wits University Press.

Mendelowitz, B. \& Dixon, K. 2016. Risky writing: Working with a heteroglossic pedagogy to deepen pre-service teachers' learning. Perspectives in Education, 34(1): 120-134.

Mendelowitz, B. 2017. Conceptualising and enacting the critical imagination through a critical writing pedagogy. English teaching: Practice and Critique (ETPC), 2(16): 178-193.

Norton, B. 2000. Identity and Language Learning: Gender, Ethnicity and Educational Change. London: Longman.

Pym, J. \& Kapp, R. 2013. Harnessing agency: Towards a learning model for undergraduate students. Studies in Higher Education, 38(2): 272-284.

Pym, J. \& Paxton, M. (eds.) 2013. Surfacing Possibilities: What it means to work with FirstGeneration Higher Education Students, Illinois: Common Ground.

Ramphele, M. 1995. A Life. Cape Town: David Philip.

Sabri, D. 2011. What's wrong with 'the student experience'? Discourse: Studies in the Cultural Politics of Education, 32(5): 657-667.

Reay, D. 2001. Finding or losing yourself? Working-class relationships to Education. Journal of Education Policy, 16(4): 333-346. 
Sacks, J. \& Kapp, R. 2017. 'Going nowhere slowly': A longitudinal perspective on a first-generation woman student's withdrawal from university. In Bangeni, B. \& Kapp, R. (eds.) Negotiating Learning and Identity: A Longitudinal Perspective on Access, Persistence and Retention in Higher Education. UK: Bloomsbury Publishing, 61-77.

Sfard, A. \& Prusak, A. 2005. Telling identities: In search of an analytic tool for investigating learning as a culturally shaped activity. Educational Researcher, 34:14-22.

Swartz, S., Mahali, A., Moletsane, R., Arogundade, E., Khalema, E., Cooper, A. \& Groenewald, C. 2018. Studying While Black. Cape Town: HSRC Press.

Thomson, R. \& Holland, J. 2003. Hindsight, foresight and insight: The challenges of longitudinal qualitative research. International Journal of Social Research Methodology, 6(3): 233-244.

Thomson, R. 2009. Unfolding Lives: Youth, Gender and Change. Bristol: Policy Press.

Thomson, R. \& McLeod, J. 2015. New frontiers in qualitative research: An agenda for research. International Journal of Social Research Methodology, 18(3): 243-250.

Thornton, R. 1988. Culture: A contemporary definition. In Boonzaier, E. \& Sharp, J. (eds.) South African Keywords. Cape Town: David Phillip, 17-28.

University of Cape Town, Curriculum Change Working Group. 2018. Curriculum Change Framework. Available at https://www.news.uct.ac.za/images/userfiles/downloads/ media/UCT-Curriculum-Change-Framework.pdf (accessed 18 July 2019).

Van Rensburg, V. \& Kapp, R. 2014. 'So I have to be positive, no matter how difficult it is': A longitudinal case study of a first-generation occupational therapy student. South African Journal of Occupational Therapy, 144(3): 29-33.

Walker, M. \& Mathebula, M. 2019. Low-income rural youth migrating to urban universities in South Africa: Opportunities and inequalities. Compare: A Journal of Comparative and International Education: 1-17. https://doi.org/10.1080/03057925.2019.1587705.

Weedon, C. 1987. Feminist Practice and Poststructuralist Theory. Cambridge, MA: Blackwell.

Wilson-Strydom, M. 2015. University Access and Success: Capabilities, Diversity and Social Justice, London and New York: Routledge and Taylor and Francis. 